OPEN

SUBJECT AREAS:

BATTERIES

CHEMICAL ENGINEERING

Received

21 November 2014

Accepted

10 February 2015

Published

11 March 2015

Correspondence and requests for materials should be addressed to

Y.M. (moritomo. yutaka.gf@u.tsukuba. ac.jp)

\title{
Fast discharge process of layered cobalt oxides due to high $\mathrm{Na}^{+}$diffusion
}

\author{
Takayuki Shibata' ${ }^{\text {, Yuya Fukuzumi }}{ }^{2}$, Wataru Kobayashi ${ }^{1,2}$ \& Yutaka Moritomo 1,2,3
}

${ }^{1}$ Fucalty of Pure and Applied Science, Univ. of Tsukuba, Tsukuba 305-8571, Japan, ${ }^{2}$ College of Physics, Univ. of Tsukuba, Tsukuba 305-8571, Japan, ${ }^{3}$ Center for Integrated Research in Fundamental Science and Engineering (CiRfSE), Univ. of Tsukuba, Tsukuba 305-8571, Japan.

Sodium ion secondary battery (SIB) is a low-cost and ubiquitous secondary battery for next-generation large-scale energy storage. The diffusion process of large $\mathrm{Na}^{+}$(ionic radius is $1.12 \AA$ ), however, is considered to be slower than that of small $\mathrm{Li}^{+}(0.76 \AA)$. This would be a serious disadvantage of SIB as compared with the Lithium ion secondary battery (LIB). By means of the electrochemical impedance spectroscopy (EIS), we determined the diffusion constant $(D)$ of $\mathrm{Na}^{+}$in thin films of $\mathrm{O} 3$ - and $\mathrm{P} 2$-type $\mathrm{NaCoO}_{2}$ with layered structures. We found that the $D$ values $\left(\sim 0.5-1.5 \times 10^{-10} \mathrm{~cm}^{2} / \mathrm{s}\right)$ of $\mathrm{Na}^{+}$are higher than those $(<1 \times$ $10^{-11} \mathrm{~cm}^{2} / \mathrm{s}$ ) of $\mathrm{Li}^{+}$in layered $\mathrm{LiCoO}_{2}$. Especially, the $D$ values of $\mathrm{O} 3-\mathrm{NaCoO}_{2}$ are even higher than those of $\mathrm{P} 2-\mathrm{NaCoO}_{2}$, probably because $\mathrm{O} 3-\mathrm{NaCoO}_{2}$ shows successive structural phase transitions from the $\mathrm{O} 3, \mathrm{O}^{\prime} 3$, P'3, to P3 phases with $\mathrm{Na}^{+}$deintercalation. We further found that the activation energy $\left(E_{D} \sim 0.4 \mathrm{eV}\right)$ for the $\mathrm{Na}^{+}$diffusion is significantly low in these layered cobalt oxides. We found a close relation between the relative capacity and the renormalized discharge rate $\left(=L^{2} / D T\right.$, where $L$ and $T$ are the film thickness and discharge time, respectively).

\footnotetext{
he SIBs store electric energy by the intercalation/deintercalation of abundant $\mathrm{Na}^{+}$(Clark number $=2.63$ ), and hence, are suitable for large-scale batteries that will enable the stable use of solar and wind energies ${ }^{1-3}$. Recently, Komaba et al. ${ }^{4}$ have found that hard carbon shows a high capacity of more than $200 \mathrm{mAh} / \mathrm{g}$ and good cyclability. This finding opens the door to the commercial utilization of SIB technologies, and hence, significantly stimulates investigation and exploration of cathode materials for SIBs. Among the cathode materials for $\mathrm{SIBs}^{1,2}$, layered transition metal oxides $\left(\mathrm{NaMO}_{2}\right.$, where $M$ is transition metal) show promising electrochemical properties $^{5,6}$ as well as rich structural properties ${ }^{7-9}$. We have much wider selections of sodium compounds, e.g., transition metal and stacking structure, as compared with those of the lithium compounds. For example, O3$\mathrm{NaCrO}_{2}$ shows a capacity of $120 \mathrm{mAh} / \mathrm{g}$ and an average operating voltage of $3.0 \mathrm{~V}$ (vs. Na) with good cyclability in $\mathrm{SIBs}^{10}$ while isostructural $\mathrm{O} 3-\mathrm{LiCrO}_{2}$ shows a poor capacity and cyclability in LIBs. In addition to the O3-type staking, i.e., close-packed $\mathrm{AB}|\mathrm{CA}| \mathrm{BC}$ stacking of oxygen sheets along the $c$-axis, the sodium compounds frequently exhibit the P2-type staking, i.e., close-packed $\mathrm{AB} \mid \mathrm{BA}$ stacking of oxygen sheets. For example, P2$\mathrm{Na}_{0.6} \mathrm{MnO}_{2}{ }^{11}$ shows a capacity of $140 \mathrm{mAh} / \mathrm{g}$ and an average operating voltage of $2.5 \mathrm{~V}$ (vs. Na). The $\mathrm{Na}$ deficiency of the P2-type compound, however, is serious drawback in the actual process of manufacture, because an extra electrochemical process is needed to compensate the $\mathrm{Na}$ deficiency.

SIBs are considered for stationaly energy storage bacause the diffusion process of large $\mathrm{Na}^{+}$(ionic radius is 1.12 $\AA)$ is believed to be slower than that of small $\mathrm{Li}^{+}(0.76 \AA)$. However, the $\mathrm{Na}^{+}$diffusion is really dependent on the crystal structure. For example, the $\mathrm{Na}^{+}$diffusion in $\mathrm{P} 2-\mathrm{Na}_{0.66} \mathrm{Li}_{0.22} \mathrm{Ti}_{0.78} \mathrm{O}_{2}$ with layered structure ${ }^{12}$ and $\mathrm{Na}_{3} \mathrm{~V}_{2}\left(\mathrm{PO}_{4}\right)_{3}{ }^{13}$ with NASICON (Na Super Ionic CONductor) structure are considerably fast, while it is much slower in $\mathrm{Li}_{4} \mathrm{Ti}_{5} \mathrm{O}_{12}{ }^{14,15}$ with spinel structure. In order to precisely determine the $\mathrm{Na}^{+}$diffusion constant $(D)$, we fabricated thin films of O3- and P2-type $\mathrm{NaCoO}_{2}$ on an Au collector electrode by means of the pulsed laser deposition (PLD) method. We found that the $D$ values $\left(\sim 0.5-1.5 \times 10^{-10} \mathrm{~cm}^{2} / \mathrm{s}\right)$ of $\mathrm{Na}^{+}$are higher than those $(1$ $\left.\times 10^{-11} \mathrm{~cm}^{2} / \mathrm{s}^{16}\right)$ of $\mathrm{Li}^{+}$in layered $\mathrm{LiCoO}_{2}$. We further extracted a close relation between the relative capacity and the renormalized discharge rate $\left(=L^{2} / D T\right)$, with eliminating the voltage drop effects, i.e., $-I R$, in the ratedependence of discharge curves.

We first determined the crystal structures of O3-type $\mathrm{Na}_{0.99} \mathrm{CoO}_{2}$ and $\mathrm{P} 2$-type $\mathrm{Na}_{0.67} \mathrm{CoO}_{2}$ by Rietveld analysis (Rietan- $\mathrm{FP}^{17}$ ) based on the synchrotron-radiation X-ray powder diffraction pattern obtained at BL02B2 beamline ${ }^{18}$ of SPring-8, Japan (Figs. S1 and S2). Figure 1 shows the $\mathrm{Na}^{+}$diffusion path of (a) O3-type $\mathrm{Na}_{0.99} \mathrm{CoO}_{2}$ and (b) P2-type $\mathrm{Na}_{0.67} \mathrm{CoO}_{2}$ together with the actual inter-oxygen distances. In the O3-type stacking, $\mathrm{Na}^{+}$is located in the oxygen octahedron and migrates to the neighboring site through the oxygen isosceles triangle, $2.84 \AA$ in base
} 
(a) $\mathrm{O} 3-\mathrm{NaCOO}_{2}$
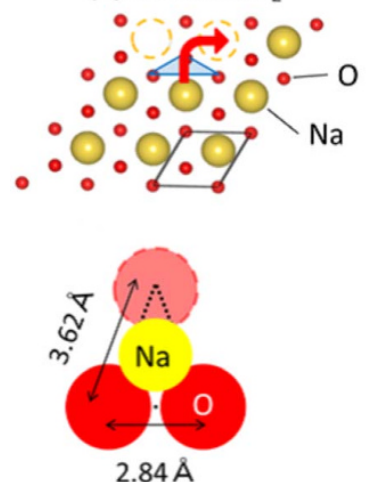

(b) $\mathrm{P} 2-\mathrm{NaCoO}_{2}$
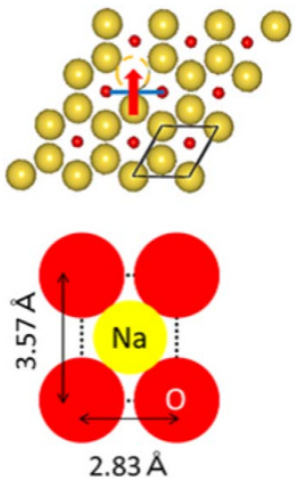

Figure $1 \mid \mathrm{Na}^{+}$diffusion path of (a) O3-type $\mathrm{Na}_{0.99} \mathrm{CoO}_{2}$ and (b) P2-type $\mathrm{Na}_{0.67} \mathrm{CoO}_{2}$. Upper panels show $\mathrm{Na}^{+}$layers (large yellow spheres) together with the sandwiching oxygen layers (small red spheres). Red arrows and blue marks indicate the $\mathrm{Na}^{+}$diffusion path and the oxygen window, respectively. Lower panels show the oxygen window together with the ionic radii of $\mathrm{Na}^{+}(1.12 \AA)$ and $\mathrm{O}^{2-}(1.40 \AA)$.

and 3.64 $\AA$ in oblique side $\mathrm{e}^{19}$. The triangle window is rather narrow for $\mathrm{Na}^{+}$: the optimal distance $(=1.97 \AA)$ to the three vertexes is much smaller than the sum $(=2.52 \AA)$ of the ionic radii of $\mathrm{Na}^{+}(1.12 \AA)$ and $\mathrm{O}^{2-}(1.4 \AA)$. In the P2-type stacking, $\mathrm{Na}^{+}$is located in oxygen triangular prism and migrates to the neighboring site through the oxygen rectangle, $2.83 \AA$ in base and $3.57 \AA$ in height. The rectangle window is wide for $\mathrm{Na}^{+}$: the optimal length $(=2.28 \AA)$ to the four vertexes is comparable the sum $(=2.52 \AA$ ) of the ionic radii. Thus, the $\mathrm{Na}^{+}$diffusion is considered to be faster in the P2-type stacking with oxygen prisms.

In order to determine $D$ and ionic charge-transfer resistance $\left(R_{\mathrm{ct}}\right)$, we performed the electrochemical impedance spectroscopy (EIS) of thin films of $\mathrm{O} 3-\mathrm{NaCoO}_{2}$ and $\mathrm{P} 2-\mathrm{NaCoO}_{2}$ (Figs. S5 and S6). The EIS curves were analyzed by least-squares fitting with the Randle equivalent circuit [Fig. 2(a)]. In the analysis, we used a constant phase element (CPE)-restricted diffusion impedance, $z_{d}(u)=$ $\frac{\alpha u^{n}+\sqrt{u} \operatorname{coth} \sqrt{u}}{u+\alpha u^{n+1 / 2} \operatorname{coth} \sqrt{u}}$ and $u=i \omega \frac{L^{2}}{D}{ }^{20}$. As shown in Fig. 2 (b), this model well reproduced the overall feature of the EIS curve, i.e., semicircle in the high-frequency region and bending behavior in the low frequency region. Especially, the CPE-restricted diffusion impedance reproduced the finite slope in the low frequency limit. Thus obtained $D$ and $R_{\mathrm{ct}}$ were plotted in Figs. 2(c) and (d). The $D$ values of O3$\mathrm{NaCoO}_{2}$ are even higher than those of $\mathrm{P} 2-\mathrm{NaCoO}_{2}$ [Fig. 2(c)], the origin of which will be discussed later. Importantly, the $D$ values ( $\left.0.5-1.5 \times 10^{-10} \mathrm{~cm}^{2} / \mathrm{s}\right)$ of $\mathrm{Na}^{+}$in layered cobalt oxides are much higher than those $\left(<1 \times 10^{-11} \mathrm{~cm}^{2} / \mathrm{s}^{16}\right)$ of $\mathrm{Li}^{+}$in $\mathrm{LiCoO}_{2}$. We note that the experimentally-obtained $D$ values in layered cobalt oxides are comparable to the calculated one $\left(\sim 2.1 \times 10^{-10} \mathrm{~cm}^{2} / \mathrm{s}^{12}\right)$ of $\mathrm{P} 2$ $\mathrm{Na}_{0.66} \mathrm{Li}_{0.22} \mathrm{Ti}_{0.78} \mathrm{O}_{2}$. In the high- $x$ region $(x>0.82)$ of $\mathrm{P} 2-\mathrm{Na}_{x} \mathrm{CoO}_{2}$, the high-frequency semicircle is too deformed to be analyzed at $303 \mathrm{~K}$ (Fig. S5). The EIS curves of $\mathrm{P} 2-\mathrm{Na}_{x} \mathrm{CoO}_{2}(x=0.5)$ show no bending behavior in the low frequency region in the temperature range from $303 \mathrm{~K}$ to $349 \mathrm{~K}$ (Fig. S6). This implies that the $D$ value at $x=0.5$ is much higher than those at $x=0.54-0.72$. This is probably due to the $\mathrm{Na}^{+}$/vacancy ordering. On the other hand, the $R_{\text {ct }}$ values of $\mathrm{O} 3-\mathrm{NaCoO}_{2}$ are much smaller than those of P2$\mathrm{NaCoO}_{2}$. We further estimated the activation energies of $D$ and $R_{\mathrm{ct}}$ by Arrhenius plot (Fig. S7). In the high- $x$ region $(x>0.82)$ of P2$\mathrm{Na}_{\mathrm{x}} \mathrm{CoO}_{2}$, the activation energies of $D$ and $R_{\mathrm{ct}}$ can be evaluated because the deformations of the EIS curves are released above $318 \mathrm{~K}$ (Fig. S6). The activation energies $\left(E_{\mathrm{D}} \sim 0.4 \mathrm{eV}\right)$ of $D$ in O3$\mathrm{NaCoO}_{2}$ are comparable to those in $\mathrm{P} 2-\mathrm{NaCoO}_{2}$. On the other hand,
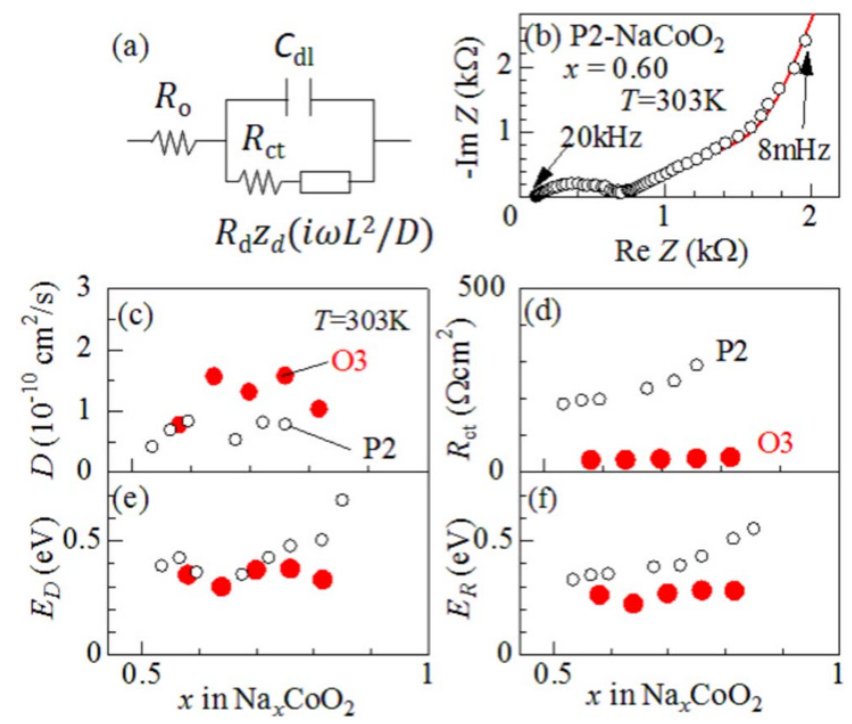

Figure $2 \mid \mathrm{Na}^{+}$diffusion constant $(D)$ and ionic charge-transfer resistance $\left(\boldsymbol{R}_{\mathrm{ct}}\right)$ of layered cobalt oxides. (a) Randles equivalent circuit: high frequency resistance of electrolyte $\left(R_{\mathrm{o}}\right)$, ionic charge-transfer resistance $\left(R_{\mathrm{ct}}\right)$, double layer capacitance $\left(C_{\mathrm{dl}}\right)$, and restricted diffusion. impedance $\left[R_{d} \times z_{d}\left(i \omega \frac{L^{2}}{D}\right), R_{\mathrm{d}}\right.$ and $z_{\mathrm{d}}$ are characteristic resistance and reduced diffusion impedance, respectively] of flat plate with thickness $L$. (b) Complex impedance of $\mathrm{P} 2-\mathrm{NaCoO}_{2}$ at $x=0.60$. Red curve is results of the least-squares fitting of with the Randles equivalent circuit: $R_{\mathrm{o}}=170 \Omega$, $R_{\mathrm{ct}}=460 \Omega, C_{\mathrm{dl}}=0.62 \mu \mathrm{F}, R_{\mathrm{d}}=2500 \Omega, D=0.83 \times 10^{-10} \mathrm{~cm}^{2} / \mathrm{s}, \alpha=0.40$ and $n=0.77$. (c) $D$, (d) $R_{\mathrm{ct}}$ (e) activation energy $\left(E_{D}\right)$ of $D$, and (f) activation energy $\left(E_{R}\right)$ of $R_{\mathrm{ct}}$. against $x$.

the activation energies $\left(E_{\mathrm{R}} \sim 0.3 \mathrm{eV}\right)$ of $R_{\mathrm{ct}}$ in $\mathrm{O} 3-\mathrm{NaCoO}_{2}$ are slightly lower than those $(\sim 0.4 \mathrm{eV})$ in $\mathrm{P} 2-\mathrm{NaCoO}_{2}$.

The open-current-voltage (OCV) discharge curve slightly different between O3-type and P2-type $\mathrm{NaCoO}_{2}$ (black curves in Fig.3). The layered cobalt oxides are known to show successive structural phase transition with $\mathrm{Na}^{+}$intercalation/deintercalation. The phase transition causes the voltage drop at single phase point and the voltage plateau in two phase region. Lie. et al. ${ }^{21}$ systematically investigated the structural properties of $\mathrm{O} 3-\mathrm{Na}_{x} \mathrm{CoO}_{2}$ against $x$. They found four phases, i.e., the O3 $(x=1.00)$, O'3 (monoclinic phase: $x=0.83$ ), $\mathrm{P}^{\prime} 3$ (monoclinic phase: $\left.x=0.67\right)$, and $\mathrm{P} 3(x \sim 0.5)$ phases. In the O'3phase, $\mathrm{Na}^{+}$is located in the oxygen octahedron as in the O3-type. In the P'3 and P3 phases, $\mathrm{Na}^{+}$is located in the oxygen prisms as in the P2-type. Actually, we observed four voltage drops in the discharge curve of $\mathrm{O} 3-\mathrm{NaCoO}_{2}$, which correspond to the $\mathrm{O} 3$,
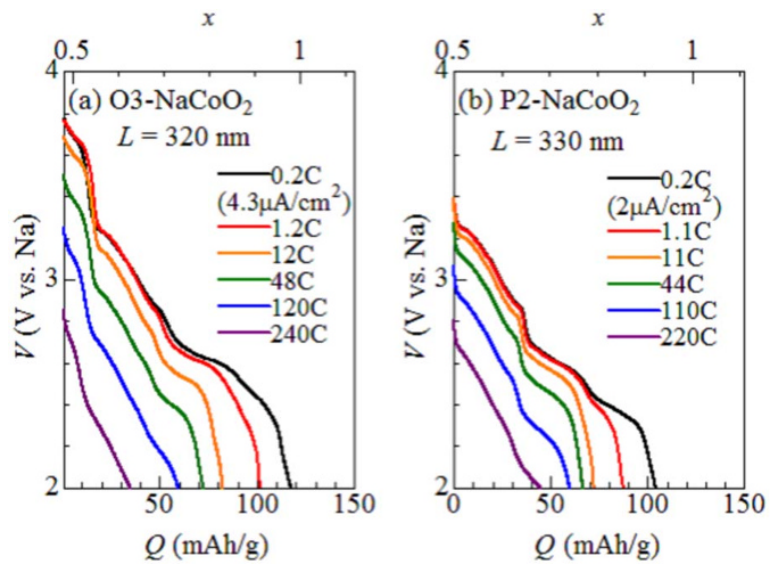

Figure 3 Discharge curves of films of (a) $\mathrm{O} 3-\mathrm{NaCoO}_{2}$ and (b) P2$\mathrm{NaCoO}_{2}$. Film thicknesses $(L)$ are $320 \mathrm{~nm}$ and $330 \mathrm{~nm}$, respectively. 
O'3, P'3 and P3 phases (Fig. S8). In addition, the inter $\mathrm{CoO}_{2}$-sheet distance $(\sim 5.44 \AA)$ of the oxidized film $(x=0.65)$ is much longer than that $(\sim 5.14 \AA$ ) of the as-grown film, (Fig. S3) suggesting the P3type structure ${ }^{21}$. These observations indicate that the $\mathrm{O} 3-\mathrm{Na}_{x} \mathrm{CoO}_{2}$ film $(0.5<x<0.83)$ contains the P3 (or P'3) phases. Then, the unexpected high- $D$ values observed in $\mathrm{O} 3-\mathrm{NaCoO}_{2}$ [see Fig.3(c)] are ascribed to the P3-type host framework with oxygen prisms. On the other hand, Berthelot et al. ${ }^{8}$ investigated the structural properties of $\mathrm{P} 2-\mathrm{Na}_{x} \mathrm{CoO}_{2}$ against $x$. They found three phases, i.e., the $x=$ $0.72,0.76$, and 0.79 phases, in addition to the well-known $x=1 / 2$ and $2 / 3$ phases. These phases are ascribed to the $\mathrm{Na}^{+} /$vacancy ordering within the P2-type host framework. We observed three voltage drops in the discharge curve of $\mathrm{P} 2-\mathrm{NaCoO}_{2}$, which correspond to the $1 / 2$, $3 / 2$, and $\sim 0.76$ phases (Fig. S8).

Figure 3 shows discharge curve of (a) $\mathrm{O} 3-\mathrm{NaCoO}_{2}$ and (b) P2$\mathrm{NaCoO}_{2}$ at various discharge rates. The fast discharge properties observed in thin films are probably ascribed to the ideal electronic contact between the active material and the collector electrode. Generally, the discharge process is governed by the electric conductivity (or voltage drop) and $\mathrm{Na}^{+}$diffusion process. We first eliminated the voltage drop effect (-IR: $I$ and $R$ is the current density and battery resistances) by changing the cut-off voltage for evaluation of the capacity ( $Q$ ) as $2.5 \mathrm{~V}-I R$. The $R$ values are $477 \Omega$ in $\mathrm{O} 3-\mathrm{NaCoO}_{2}$ $(L=320 \mathrm{~nm}), 660 \Omega$ in $\mathrm{O} 3-\mathrm{NaCoO}_{2}(L=330 \mathrm{~nm})$, and $1160 \Omega$ in $\mathrm{O} 3-\mathrm{NaCoO}_{2}(L=170 \mathrm{~nm})$. Then, the residual rate-dependence can be ascribed to the $\mathrm{Na}^{+}$diffusion effect. Here, let us consider onedimensional diffusion equation, $\frac{\partial n}{\partial t}=D \frac{\partial^{2} n}{\partial x^{2}}$, where $n$ is the $\mathrm{Na}^{+}$density. We introduce dimensionless time and depth scales, i.e., $\alpha(=x /$ $L)$ and $\beta(=t / T)$, where $T$ is the time needed for the full discharge. In other words, system is fully-discharged at $\beta=1$. Then, we obtained a renormalized diffusion equation, $\frac{\partial n}{\partial \beta}=\frac{D T}{L^{2}} \frac{\partial^{2} n}{\partial \alpha^{2}}$. This equation indicates that the diffusion dynamics scales with the renormalized discharge rate $\left(L^{2} / D T\right)$, irrespective of the individual $L, D$, and $T$ values.

Figure 4 shows relative capacities $\left(Q / Q_{0}: Q_{0}\right.$ is the OCV capacity) of three films against $L^{2} / D T$. The $Q / Q_{0}$ value begins to decrease when $L^{2} / D T$ approaches $\sim 0.1$ while it remain nearly $\sim 1$ in the small- $L^{2} /$ $D T$ region. The decrease, commonly observed in three films, should be ascribed to the $\mathrm{Na}^{+}$diffusion process. The solid curve in Fig.4 is the result of simulation of discharge process. The simulation was performed by difference calculus with the space mesh $\left(N_{\alpha}\right)$ of 30 and time mesh $\left(N_{\beta}\right)$ of 20,000 (Fig. S9). At the active material/electrolyte boundary $(\alpha=0)$, we forces a constant $\mathrm{Na}^{+}$intercalation $(=$ $\left.N_{\alpha} / N_{\beta}\right)$. The $\mathrm{Na}^{+}$intercalation stops if the density $(=1-n)$ of the $\mathrm{Na}^{+}$vacancy at $\alpha=0$ becomes smaller than $N_{\alpha} / N_{\beta}$. The $\beta$ value at this condition corresponds to $Q / Q_{0}$. The simulated curve begins to decreases at $L^{2} / D T \sim 0.1$, and well reproduces the global feature of the experiment.

In summary, we fabricated thin films of O3- and P2-type $\mathrm{NaCoO}_{2}$ by means of the PLD method and precisely determined the magnitudes and activation energies of $D$ and $R_{\mathrm{CT}}$. We found that the $D$ values $\left(\sim 0.5-1.5 \times 10^{-10} \mathrm{~cm}^{2} / \mathrm{s}\right)$ for the $\mathrm{Na}^{+}$diffusion are much higher than those $\left(<1 \times 10^{-11} \mathrm{~cm}^{2} / \mathrm{s}^{16}\right)$ for the $\mathrm{Li}^{+}$diffusion in layered cobalt oxides. Especially, the $D$ values of $\mathrm{O} 3-\mathrm{NaCoO}_{2}$ are even higher than those of $\mathrm{P} 2-\mathrm{NaCoO}_{2}$. This is probably because oxidized O3$\mathrm{Na}_{x} \mathrm{CoO}_{2}$ film $(0.5<x<0.83)$ contains the P3-type host framework with oxygen prisms. We further found that the activation energy $\left(E_{D}\right.$ $\sim 0.4 \mathrm{eV}$ ) for the $\mathrm{Na}^{+}$diffusion is significantly low in these layered cobalt oxides. Our experiment indicates that we can explore active materials with high $\mathrm{Na}^{+}$diffusion even though the diffusion process of larger $\mathrm{Na}^{+}$was believed to slower than that of small $\mathrm{Li}^{+}$.

\section{Method}

Film synthesis and characterization. This film of $\mathrm{O} 3-\mathrm{NaCoO}_{2}\left(\mathrm{P} 2-\mathrm{NaCoO}_{2}\right)$ was grown on Au-deposited $\mathrm{MgO}(100)$ substrate at $823 \mathrm{~K}(923 \mathrm{~K})$ in an oxygen partial

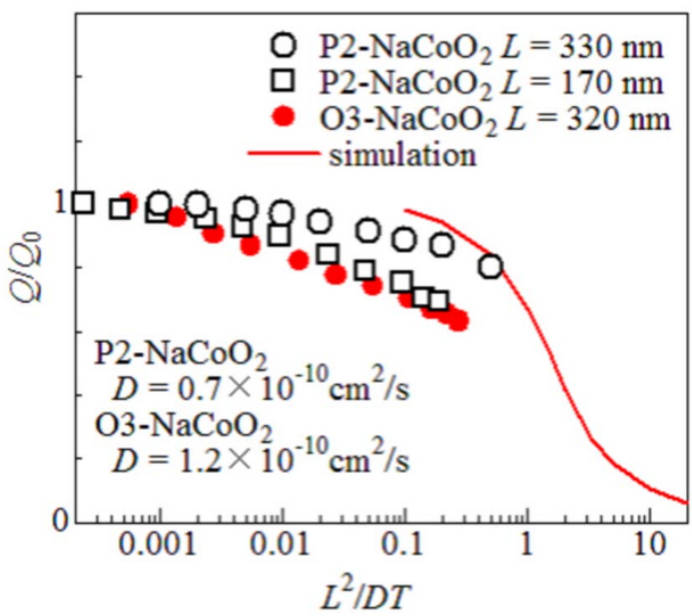

Figure $4 \mid$ Relative capacity $\left(Q / Q_{0}\right)$ against renormalized discharge rate $\left(L^{2} / D T\right) . L, D$, and $T$ are the film thickness, $\mathrm{Na}^{+}$diffusion constant, and discharge time, respectively. $Q_{0}$ and $Q$ are the open-current-voltage (OCV) capacity and actual capacity, respectively. The capacities are evaluated at $2.5 \mathrm{~V}-I R$, where $I$ and $R$ is the current density and battery resistances. Solid curve is the results of simulation based on the one-dimensional diffusion equation. The data of $\mathrm{P} 2-\mathrm{NaCoO}_{2}$ (open squares) were cited from ref. 22.

pressure of $0.01 \mathrm{~Pa}(50 \mathrm{~Pa})$ for 10-30 min by pulsed laser deposition (PLD) method. The film thickness $(L)$ was $200-400 \mathrm{~nm}$, and the film area was $0.5 \mathrm{~cm}^{2} . L$ was determined by cross-sectional SEM image, after the electrochemical measurements. The mass of the active material was estimated by $L$ and the actual density of the film, which was evaluated with a larger and thicker film. The second harmonics of an yttrium-aluminum-garnet (YAG) pulse laser was used as excitation light source. The pulse energy, repetition frequency, and wavelength were $2.0 \mathrm{~J} / \mathrm{cm}^{2}, 10 \mathrm{~Hz}$, and $532 \mathrm{~nm}$, respectively. The distance between the target and the substrate was $35 \mathrm{~mm}$. The sodium concentration of the film was assumed to be the same as the target, which was determined by Rietveld structural analysis (Figs. S1 and S2). The targets of O3$\mathrm{Na}_{0.99} \mathrm{CoO}_{2}\left(\mathrm{P} 2-\mathrm{Na}_{0.67} \mathrm{CoO}_{2}\right)$ were prepared by solid state reaction. First, $\mathrm{Na}_{2} \mathrm{O}_{2}$ $\left(\mathrm{Na}_{2} \mathrm{CO}_{3}\right)$ and $\mathrm{Co}_{3} \mathrm{O}_{4}$ were mixed in a 1.25: $1.0(0.7: 1.0)$ atomic ratio and calcined at $823 \mathrm{~K}(1073 \mathrm{~K})$ for $16 \mathrm{~h}(12 \mathrm{~h})$ in $\mathrm{O}_{2}$ atmosphere (air). Then, the $\mathrm{O} 3-\mathrm{NaCoO}_{2}(\mathrm{P} 2$ $\mathrm{NaCoO}_{2}$ ) powder was finely ground, pressed into pellets with $2 \mathrm{~mm}$ in diameter, and calcined at $823 \mathrm{~K}(1073 \mathrm{~K})$ for $16 \mathrm{~h}(12 \mathrm{~h})$ in $\mathrm{O}_{2}$ atmosphere (air). We confirmed the (003) and (006) [(002) and (004)] reflections in the X-ray diffraction pattern (Fig. S3) of $\mathrm{O} 3-\mathrm{NaCoO}_{2}\left(\mathrm{P} 2-\mathrm{NaCoO}_{2}\right)$, indicating the (001)-orientation of the films. The scanning electron microscope (Fig. S4) revealed that the O3- $\mathrm{NaCoO}_{2}\left(\mathrm{P} 2-\mathrm{NaCoO}_{2}\right)$ film consists of grains of $\sim 100 \mathrm{~nm}(300-500 \mathrm{~nm})$ in diameter.

Electrochemical measurement. The discharge properties were investigated using a two-pole beaker type cell with a battery charge/discharge system (HOKUTO HJSD8). The cathode and anode were the film and $\mathrm{Na}$, respectively. The electrolyte was propylene carbonate (PC) containing $1 \mathrm{~mol} / \mathrm{L} \mathrm{NaClO}_{4}$. The lower and upper cut-off voltages vs. $\mathrm{Na}$ were $1.5 \mathrm{~V}(2.0 \mathrm{~V})$ and $3.8 \mathrm{~V}(3.4 \mathrm{~V})$ for $\mathrm{O} 3-\mathrm{NaCoO}_{2}\left(\mathrm{P} 2-\mathrm{NaCoO}_{2}\right)$, respectively. The charge current was set to $4 \mu \mathrm{A} / \mathrm{cm}^{2}$. The electrochemical impedance spectroscopy (EIS) was carried out with a potentiostat (BioLogic VSP). The frequency range was from $5 \mathrm{mHz}$ to $200 \mathrm{kHz}$, and the amplitude was $30 \mathrm{mV}$.

Analysis of the EIS data. The EIS data were analyzed by Randles equivalent circuit [see Fig. 2(a)] with high frequency resistance of electrolyte $\left(R_{\mathrm{o}}\right)$, ionic charge-transfer resistance $\left(R_{\mathrm{ct}}\right)$, double layer capacitance $\left(C_{\mathrm{dl}}\right)$, and restricted diffusion impedance $\left[R_{d} \times z_{d}\left(i \omega \frac{L^{2}}{D}\right), R_{\mathrm{d}}\right.$ and $z_{\mathrm{d}}$ are characteristic resistance and reduced diffusion impedance, respectively] of flat plate with thickness $L$. We used the CPE-restricted form, $z_{d}(u)=\frac{\alpha u^{n}+\sqrt{u} \operatorname{coth} \sqrt{u}}{u+\alpha u^{n+1 / 2} \operatorname{coth} \sqrt{u}}$ and $u=i \omega \frac{L^{2}}{D}{ }^{20}$. The CPE-restricted diffusion $u+\alpha u^{n+1 / 2} \operatorname{coth} \sqrt{u} \quad D$
impedance becomes the well-known forms in special cases: $z_{d}(u)=\frac{1}{\sqrt{u}} \operatorname{coth} \sqrt{u}$ at $\alpha=0$ (perfectly-reflective boundary) and $z_{d}(u)=\frac{1}{\sqrt{u}} \tanh \sqrt{u}$ at $\alpha=\infty$ (perfectlyabsorptive boundary). The seven parameters, i.e., $R_{\mathrm{o}}, R_{\mathrm{ct}}, C_{\mathrm{dl}}, R_{\mathrm{D}}, \alpha, n$, and $D$, were determined by least-squares fittings of the EIS curves.

1. Kim, S.-W., Seo, D.-H., Ma, X., Ceder, G. \& Kang, K. Electrode materials for rechargeable sodium-ion batteries: potential alternatives to current lithium-ion batteries. Adv. Energy Mater. 2, 710-721 (2010). 
2. Ong, S. P. et al. Voltage, stability and diffusion barrier differences between sodium-ion and lithium-ion intercalation materials. Energy Environ. Sci. 4, 3680-3688 (2011).

3. Pan, H., Hu, Y.-S. \& Chen, L. Room-temperature stationary sodium-ion batteries for large-scale electric energy storage. Energy Environ. Sci. 6, 2338-2360 (2013).

4. Komaba, S. et al. Electrochemical $\mathrm{Na}$ insertion and solid electrolyte interphase for hard-carbon electrodes and application to Na-ion batteries. Adv. Energy Mater. 21, 3859-3567 (2011)

5. Yabuuchi, N. et al. P2-type $\mathrm{Na}_{x}\left[\mathrm{Fe}_{1 / 2} \mathrm{Mn}_{1 / 2}\right] \mathrm{O}_{2}$ made from earth-abundant elements for rechargeable $\mathrm{Na}$ batteries. Nature Mater. 11, 512-517 (2012)

6. Yoshida, H., Yabuuchi, N. \& Komaba, S. $\mathrm{NaFe}_{0.5} \mathrm{Co}_{0.5} \mathrm{O}_{2}$ as high energy and power positive electrode for $\mathrm{Na}$-ion batteries. Electrochem. Commun. 34, 60-63 (2013).

7. Medarde, M. et al. $1 \mathrm{D}$ to $2 \mathrm{D} \mathrm{Na}^{+}$ion diffusion inherently linked to structural transitions in $\mathrm{Na}_{0.7} \mathrm{CoO}_{2}$. Phys. Rev. Lett. 110, 266401 (2013).

8. Berthelot, R., Carlier, D. \& Delmas, C. Electrochemical investigation of P2$\mathrm{Na}_{\mathrm{x}} \mathrm{CoO}_{2}$ phase diagram. Nature Mater. 10, 74-80 (2010).

9. Li, X. et al. Direct visualization of the Jahn-Teller effect coupled to Na ordering in $\mathrm{Na}_{5 / 8} \mathrm{MnO}_{2}$. Nature Mater. 13, 586-592 (2014).

10. Komaba, S., Takei, C., Nakayama, T., Ogata, A. \& Yabuuchi, N. Electrochemical intercalation activity of layered $\mathrm{NaCrO}_{2}$ vs. $\mathrm{LiCrO}_{2}$. Electrochem. Commun. 12, 355-358 (2010).

11. Caballero, A. et al. Synthesis and characterization of high-temperature hexagonal P2- $\mathrm{Na}_{0.6} \mathrm{MnO}_{2}$ and its electrochemical behavior as cathode in sodium cells. J. Mater. Chem. 12, 1142-1147 (2002).

12. Wang, Y.et al. A zero-strain layered metal oxide as the negative electrode for longlife sodium-ion batteries. Nature Commun. 4, 2365-2370 (2013).

13. Jian, Z. et al. Superior electrochemical performance and storage mechanism of $\mathrm{Na}_{3} \mathrm{~V}_{2}\left(\mathrm{PO}_{4}\right)_{3}$ cathode for room-temperature sodium-ion batteries. Adv. Energy Meter. 3, 156-160 (2013)

14. Sun, S. et al. Direct atomic-scale confirmation of three-phase stage mechanism in $\mathrm{Li}_{4} \mathrm{Ti}_{5} \mathrm{O}_{12}$ anodes for room-temperature sodium-ion batteries. Nature Commun. 4, 2365-2370 (2013)

15. $\mathrm{Yu}, \mathrm{X}$. et al. A size-dependent sodium storage mechanism in $\mathrm{Li}_{4} \mathrm{Ti}_{5} \mathrm{O}_{12}$ investigated by a novel characterization technique combining in situ X-ray diffraction and chemical sodiation. Nano Lett. 13, 4721-4727 (2013).

16. Xia, H., Meng, Y. S., Lu, L. \& Ceder, G. Electrochemical behavior and Li diffusion study of $\mathrm{LiCoO}_{2}$ thin film electrode prepared by PLD. J. Power Sources 159, 1422-1427 (2006).

17. Izumi, F. \& Momma, K. Three-dimensional visualization in powder diffraction, $J$ Solid State Phemom. 130, 15-20 (2007).

18. Nishibori, E. et al. The large Debye-Scherrer camera installed at SPring-8 BL02B2 for charge density studies. Nucl. Instrum. Methods Phys. Res., Sect. A 467-468, 1045-1048 (2001).
19. Van der Ven, A., Ceder, G., Asta, M. \& Tepesch, P. D. First-principles theory of ionic diffusion with nondilute carriers. Phys. Rev. B64, 184307 (2001).

20. Bisquert, J., Garcia-Belmonte, G., Fabregat-Santiago, F. \& Bueno, P. R. Theoretical models for ac impedance of finite diffusion layered exhibiting low frequency dispersion. J. Electroanal. Chemistry 475, 152-163 (1999).

21. Lei, Y., Lie, X., Liu, L. \& Ceder, G. Synthesis and stoichiometry of different layered sodium cobalt oxides. Chem, Mater. 26, 5288-5298 (2014).

22. Shibata, T., Kobayashi, W. \& Moritomo, Y. Intrinsic rapid $\mathrm{Na}^{+}$intercalation observed in $\mathrm{Na}_{x} \mathrm{CoO}_{2}$ thin film. AIP Advance 3, 032104 (2013).

\section{Acknowledgments}

This work was supported by a Grant-in-Aid (No. 23684022) for Scientific Research from the Ministry of Education, Culture, Sports, Science and Technology, Japan. The synchrotron-radiation X-ray powder diffraction experiments were performed at the SPring-8 BL02B2 beamline with the approval (2014A1056 and 2012B1753) of the Japan Synchrotron Radiation Research Institute (JASRI).

\section{Author contributions}

Y. M. planed the overall the experiment and wrote the main manuscript. T. S. synthesized the thin films and analyzed the impedance spectra. K. W. fabricated the PLD chamber and Y. F. make a least-squares fitting program with the CPE-restricted diffusion impedance.

\section{Additional information}

Supplementary information accompanies this paper at http://www.nature.com/ scientificreports

Competing financial interests: The authors declare no competing financial interests. How to cite this article: Shibata, T., Fukuzumi, Y., Kobayashi, W. \& Moritomo, Y. Fast discharge process of layered cobalt oxides due to high $\mathrm{Na}^{+}$diffusion. Sci. Rep. 5, 9006; DOI:10.1038/srep09006 (2015).

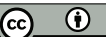

This work is licensed under a Creative Commons Attribution 4.0 International License. The images or other third party material in this article are included in the article's Creative Commons license, unless indicated otherwise in the credit line; if the material is not included under the Creative Commons license, users will need to obtain permission from the license holder in order to reproduce the material. To view a copy of this license, visit http://creativecommons.org/licenses/by/4.0/ 